\title{
RELAÇÕES GRANULOMÉTRICAS NO PROCESSO DE BRUNIMENTO DE ARROZ
}

\section{CARLOS A. S. LUZ ${ }^{1}$, MARIA L. G. S. DA LUZ ${ }^{2}$, LUCIANO T. BIZZI ${ }^{3}$, CÉSAR L. FALK ${ }^{3}$, EDER P. ISQUIERDO ${ }^{3}$, RUDIMAR LOREGIAN ${ }^{3}$}

RESUMO: O brunimento é uma das etapas de beneficiamento do arroz que tem grande importância sobre o rendimento de engenho. Neste trabalho, analisaram-se relações granulométricas de frações de grãos na massa de arroz e seus efeitos sobre o rendimento de engenho, durante o processo de brunimento. As amostras usadas foram $78 \mathrm{~g}$ de arroz descascado, tendo essas partido de amostras originais de 100 g. Foram testadas cinco relações de composição de amostras a serem brunidas, variando as quantidades de grãos quebrados e de quirera que acompanhavam a massa de grãos inteiros, que foram: 1) somente grãos inteiros; 2) 6,16 g de quebrados e 1,04 g de quirera, conforme amostra original; 3) 3,60 g de quebrados e 3,60 g de quirera adicionados aos inteiros; 4) 7,20 g de quebrados adicionados aos inteiros, e 5) 7,20 g de quirera adicionada aos inteiros. Os procedimentos foram executados com uso de engenho de provas e com classificação manual. O rendimento de engenho foi significativamente superior, após a operação de brunimento de arroz, quando existem, na massa a ser brunida, grãos quebrados e quirera, variando entre $3,60 \mathrm{~g}$ a 7,20 g e 1,04 g a 7,20 g, respectivamente, comparada ao brunimento da massa composta por $100 \%$ de grãos inteiros.

PALAVRAS-CHAVE: teste de engenho, arroz, grãos quebrados.

\section{GRANULOMETRY RELATIONSHIP IN THE RICE MILLING PROCESS}

\begin{abstract}
Milling yield using five different rates of broken and head rice was tested. The samples were arranged to have different amounts of big and small broken kernels in the mass of grains. The size of each fraction of broken grains was established according to the Brazilian Rules of Rice Classification. The paddy sample had $100 \mathrm{~g}$ and the brown rice sample had $78 \mathrm{~g}$. The brown rice was milled by adding different proportions of broken kernels to make five treatments as follows: 1) only whole kernels; 2) $6.16 \mathrm{~g}$ of big broken kernels and $1.04 \mathrm{~g}$ of small broken kernels were used as they appear in the original lot; 3) $3.6 \mathrm{~g}$ of big broken kernels and $3.6 \mathrm{~g}$ of small broken kernels were added to the whole kernels; 4) $7.2 \mathrm{~g}$ of big broken kernels were added to the whole kernels and 5) $7.2 \mathrm{~g}$ of small broken kernels were added to the whole kernels. A laboratory mill was used. The classification was made manually. The percentages of broken kernels varied from $3.6 \%$ to $7.2 \%$ in the fraction of big broken kernels and from $1.04 \%$ to $7.2 \%$ in the fraction of small broken kernels, respectively. The results showed that, in the milling process using broken kernels in the mass, the head rice yield was significantly higher than when $100 \%$ of head kernels were milled.
\end{abstract}

KEYWORDS: milling test, rice, broken kernels.

\footnotetext{
${ }^{1}$ Engo ${ }^{\mathrm{o}}$ Agrícola, Prof. Adjunto, Ph.D, Departamento de Engenharia Agrícola, Faculdade de Engenharia Agrícola, UFPel, Pelotas - RS, Fone: (0XX53) 275.7317, caluz@terra.com.br

${ }^{2}$ Eng ${ }^{a}$ Agrícola, Prof. Adjunto, Ph.D, Departamento de Engenharia Agrícola, FEA/UFPel, Pelotas - RS.

${ }^{3}$ Acadêmicos da Faculdade de Engenharia Agrícola, UFPel, Pelotas - RS.

Recebido pelo Conselho Editorial em: 11-10-2002

Aprovado pelo Conselho Editorial em: 17-12-2004
} 


\section{INTRODUÇÃO}

A produção de arroz no mundo, em 2003, foi de 589.125.843 toneladas. O Brasil foi o nono produtor mundial e o primeiro da América Latina (FAO, 2004), com produção de 10.319.925 toneladas. O Rio Grande do Sul participou com 4.708.695 toneladas na safra 2002-2003, sendo essa cultura uma de suas principais fontes econômicas (FAO, 2004; INSTITUTO RIOGRANDENSE DO ARROZ, 2004; IBGE, 2004; BRASIL, 2004).

O beneficiamento do arroz é composto de diferentes operações unitárias, entre as quais o brunimento, que determina um dos mais importantes critérios de qualidade do arroz. O objetivo do brunimento é remover do arroz integral a película de tegumento e o germe, com o mínimo de dano ao grão inteiro, preservando sua forma original. Esse material removido constituirá o farelo, que é composto pelas porções anteriormente citadas, somadas a algum endosperma amiláceo que venha a ser removido.

O valor comercial do arroz é obtido em função do rendimento de engenho, o qual é determinado pela relação entre as quantidades de grãos inteiros e quebrados. O rendimento de engenho é estabelecido após o descascamento e o brunimento do arroz, e é calculado a partir de uma quantidade de arroz em casca, em geral de $100 \mathrm{~g}$ (HOUSTON, 1972).

As operações unitárias de beneficiamento de arroz são responsáveis por cerca da metade do total de grãos quebrados, sendo que o brunimento exerce importante papel, o restante dos grãos quebrados é proveniente principalmente da lavoura. $\mathrm{O}$ valor de mercado dos grãos inteiros foi e continua sendo muito maior do que para os grãos quebrados. O preço difere em mais de $100 \%$ para grãos inteiros beneficiados. $\mathrm{O}$ aumento de 1 ou $2 \%$ no rendimento de engenho pode aumentar muito o lucro, quando grandes quantidades de grãos estão envolvidas no processo. $\mathrm{O}$ arroz quebrado é um produto aceito para consumo humano em poucos países. Uma vez que o valor econômico do grão inteiro é maior, o aumento no rendimento de grãos inteiros é de grande interesse (SPADARO et al., 1980).

O brunimento do arroz é realizado por abrasão, por meio do contato dos grãos contra uma superfície áspera em movimento. O polimento do arroz, uma operação posterior ao brunimento, de acabamento, ocorre quando os grãos são atritados uns contra os outros, ao mesmo tempo em que o arroz é submetido a uma leve pressão (SPADARO et al., 1980).

O grau de brunimento é dado em relação à quantidade de farelo removida do grão. Em geral, há quatro graus de brunimento: bem brunido, razoavelmente bem brunido, levemente brunido e nãobrunido; mas não há uma definição precisa desses termos. Sendo assim, o grau de brunimento é comumente determinado por inspeção visual ou por meio de aparelhos óticos. A maioria dos consumidores prefere arroz bem brunido, devido à sua maior brancura. Entretanto, para obter um arroz bem brunido, o rendimento de engenho diminui, com a conseqüente perda de valor comercial (HOUSTON, 1972).

São vários os fatores que contribuem para a quebra do arroz durante o brunimento, entre os quais fissuras ocorridas antes da colheita, secagem muito rápida, grãos imaturos, grãos gessados, distribuição da umidade nos grãos (BHATTACHARYA, 1969; WADWORTH \& MATTHEUS, 1985).

VELUPILLAI \& PANDEY (1990) investigaram a quebra de arroz, durante o descascamento e o brunimento, para quantidades conhecidas de cereais fissurados, e verificaram que a presença de cereais fissurados possui uma forte influência na redução do rendimento de engenho, sendo que, para níveis acima de $10 \%$ de grãos fissurados, a redução no rendimento de engenho foi maior. 
WADSWORTH et al. (1982) estudaram a relação entre espessura dos grãos de arroz e a qualidade dos produtos do arroz brunido e verificaram que a retirada de arroz com espessura inferior a 1,6 $\mathrm{mm}$ melhora a qualidade do produto final.

Algumas unidades de beneficiamento de arroz adotam a separação da porção de quebrados contida na massa de arroz inteiro, antes do processo de brunimento. Outras unidades executam o processo de brunimento com o lote original, sem a remoção de quebrados. O questionamento sobre a granulometria adequada para obtenção de maior rendimento de engenho motivou o desenvolvimento desta pesquisa.

\section{MATERIAL E MÉTODOS}

Os grãos de arroz descascados e sem brunimento foram doados por um engenho de arroz de Pelotas. Segundo o laboratório de análise de qualidade da empresa, a renda do lote usado foi de $78 \%$, conseqüentemente, tendo sido removidos $22 \%$ de casca. A umidade do lote foi de $13,41 \%$, calculada pela média de quatro amostras de $20 \mathrm{~g}$, utilizando o método de estufa a $105{ }^{\circ} \mathrm{C} \pm 3{ }^{\circ} \mathrm{C}$ por $24 \mathrm{~h}$ (BRASIL, 1989). O lote foi homogeneizado, e as amostras foram colocadas em sacos plásticos individuais e etiquetadas.

A prática usual em engenho de provas é trabalhar com amostras de $100 \mathrm{~g}$ de arroz em casca. $\mathrm{Na}$ etapa posterior, o brunimento, o peso da amostra de arroz é reduzido, pois a porção de casca é retirada. A metodologia adotada foi colocar no brunidor do engenho de provas amostras de arroz descascado, pesando $78 \mathrm{~g}$ cada.

O arroz utilizado no experimento foi classificado usando-se para isso as medidas de comprimento, largura e espessura. As medidas das dimensões dos grãos, provenientes de médias de 20 repetições, estão apresentadas na Tabela 1.

TABELA 1. Valores médios das dimensões dos grãos, provenientes de 20 medições.

\begin{tabular}{cccc}
\hline Comprimento $(\mathrm{mm})$ & Largura $(\mathrm{mm})$ & Espessura $(\mathrm{mm})$ & Relação Comprimento/Largura \\
\hline 7,12 & 2,19 & 1,79 & 3,25 \\
\hline
\end{tabular}

Tendo em vista esses resultados, o arroz pesquisado foi classificado como sendo longo-fino, uma vez que possui comprimento maior que $6 \mathrm{~mm}$, espessura menor do que $1,90 \mathrm{~mm}$ e a relação comprimento/largura superior a 2,75, de acordo com as normas de identidade do arroz (BRASIL, 1989).

Na Tabela 2, apresentam-se os valores de grãos com defeitos representativos do experimento. Esses defeitos são classificados conforme as Normas de Classificação vigentes e estão todos dentro do limite admissível pela mesma, considerando o arroz tipo 1 . O teor de arroz vermelho do lote de arroz descascado estudado foi de $4,25 \%$.

TABELA 2. Valores médios de grãos com defeitos do lote (\% peso) após brunimento e valores limites admitidos pela legislação.

\begin{tabular}{|c|c|c|c|c|c|c|c|}
\hline Defeitos & Amarelos & Manchados & Gessados & Picados & Rajados & Mal Brunidos & Mofados \\
\hline Observação & 0,08 & 0,04 & 0,40 & 0,33 & 2,81 & 0,13 & 0,17 \\
\hline Limite máx. & & & $\Sigma=4,0$ & & & - & 0,25 \\
\hline
\end{tabular}

A classificação das porções em inteiros, quebrados e quirera foi feita de acordo com as Normas de Classificação do Arroz (BRASIL, 1989) e com o uso de paquímetro. Foram medidas as três dimensões de 20 grãos de arroz, tomados aleatoriamente do lote para sua caracterização. As amostras 
de $78 \mathrm{~g}$ foram preparadas, de modo a serem obtidos cinco diferentes tratamentos, seja removendo, seja adicionando quebrados e quirera à amostra original. A separação dos quebrados computados no experimento foi realizada com o uso do 'trieur' $\mathrm{n}^{\mathrm{o}} 1$ (alvéolos de $5 \mathrm{~mm}$ de diâmetro), indicado para grãos longos, conforme recomendação do fabricante do engenho de provas, marca Suzuki. O tempo de separação no 'trieur' dos quebrados descascados e dos quebrados brunidos foi de 1 minuto por amostra. A separação da quirera foi realizada com o uso de uma peneira manual de furos redondos com 1,6 mm de diâmetro, conforme BRASIL (1989), sendo as porções pesadas em balança analítica de precisão.

O tempo de duração do brunimento no engenho de provas foi determinado por meio de testes preliminares, nos quais foram usados os tempos de 20; 40; 60 e 80 segundos. Essas amostras, então, foram submetidas a teste de brancura, transparência e brunimento no medidor Satake Milling Meter, modelo MM1B. Ficou estabelecido neste experimento, como padrão para o brunimento, o tempo de 1 minuto e 10 segundos, levando em conta os resultados lidos no aparelho e avaliação visual geral das amostras. Esse tempo também está de acordo com o tempo usado nas empresas beneficiadoras de arroz da região de Pelotas. Os valores obtidos estão apresentados na Tabela 3.

TABELA 3. Índices obtidos para diferentes tempos de brunimento, usando equipamento para determinação do grau de brunimento (Satake).

\begin{tabular}{cccc}
\hline Tempo (s) & Brancura (\%) & Transparência (\%) & Grau de Brunimento (pontos) \\
\hline 20 & 35,6 & 1,91 & 70 \\
40 & 42,0 & 2,52 & 103 \\
60 & 45,3 & 2,54 & 118 \\
80 & 47,4 & 2,72 & 128 \\
Amplitude de leitura & $15-60 \%$ & $0-9,99 \%$ & $0-199$ \\
\hline
\end{tabular}

Cada um dos cinco tratamentos teve dez repetições. Para o brunimento de cada repetição, foi realizado um sorteio entre as 50 repetições. Os tratamentos de brunimento foram executados conforme a Tabela 4. O tratamento 1 foi constituído apenas de grãos inteiros e, no tratamento 2, as porções estabelecidas para os quebrados e a quirera foram baseadas nas quantidades da amostra original, a qual continha 6,16 g de quebrados e 1,04 g de quirera, totalizando 7,20 g como sendo a fração não-inteira. Para o tratamento 3, foi escolhido usar 50\% de quebrados, ou seja, 3,60 g, e 50\% de quirera, também 3,60 g, provenientes da soma das porções de quebrados e quirera existentes, isto é, 7,20 g. No tratamento 4, as 7,20 g usadas foram constituídas somente de quebrados e, no tratamento 5, as 7,20 g foram constituídas apenas de quirera.

TABELA 4. Composição das porções nos tratamentos (g) do experimento.

\begin{tabular}{ccccc}
\hline Tratamento & Inteiros & Quebrados & Quirera & Total \\
\hline 1 & 78,00 & 0,00 & 0,00 & 78,00 \\
2 & 70,80 & 6,16 & 1,04 & 78,00 \\
3 & 70,80 & 3,60 & 3,60 & 78,00 \\
4 & 70,80 & 7,20 & 0,00 & 78,00 \\
5 & 70,80 & 0,00 & 7,20 & 78,00 \\
\hline
\end{tabular}

O delineamento estatístico usado para análise dos dados obtidos foi completamente ao acaso. A comparação das médias foi feita segundo o teste de Duncan, a $\mathrm{p}<5 \%$. Foi realizado o teste de Kolmogorov-Smirnov para testar a normalidade dos dados nos grupos de tratamentos (CONOVER, 1980). A homogeneidade de variâncias foi verificada segundo teste de Levene (VIEIRA, 1999). As 
médias e as variâncias foram avaliadas para verificar a independência entre os efeitos de tratamentos e efeitos do erro.

\section{RESULTADOS E DISCUSSÃO}

Os dados gerais de todo o experimento são mostrados na Tabela 5. Essa tabela contém os cálculos das diferenças entre grãos descascados (esbramados) e grãos brunidos para cada porção constituinte da massa de grãos do experimento.

Observando-se a Tabela 5, ao comparar os tratamentos, nota-se que em geral houve tendência de aumento da porção de quebrados, após o brunimento, inversamente proporcional à quantidade de quebrados existente na amostra inicial a ser brunida. Os tratamentos 1 e 5, que inicialmente não possuíam grãos quebrados, apresentaram maior porcentual proporcional dessa fração do que nos demais tratamentos, os quais possuíam inicialmente grãos quebrados. Comparando os tratamentos 4 e 5 entre si, observa-se que a granulometria da fração dos quebrados tem maior influência na manutenção dos grãos inteiros da amostra do que a fração de quirera.

TABELA 5. Valores médios de dez repetições, em gramas (g), dos grãos de arroz inteiros e suas porções menores, nas várias condições utilizadas no experimento.

\begin{tabular}{|c|c|c|c|c|c|}
\hline \multirow{2}{*}{$\begin{array}{l}\text { Porções da Massa de Grãos } \\
\qquad(\mathrm{g})\end{array}$} & \multicolumn{5}{|c|}{ Tratamentos* } \\
\hline & 1 & 2 & 3 & 4 & 5 \\
\hline Inteiros esbramados & 78,00 & 70,80 & 70,80 & 70,80 & 70,80 \\
\hline Inteiros brunidos & 62,78 & 57,01 & 57,19 & 57,06 & 56,83 \\
\hline Diferença entre inteiros & 15,22 & 13,79 & 13,61 & 13,74 & 13,97 \\
\hline Quebrados esbramados & 0,00 & 6,16 & 3,60 & 7,20 & 0,00 \\
\hline Quebrados brunidos & 3,49 & 6,82 & 5,15 & 6,95 & 3,19 \\
\hline Diferença entre quebrados & 3,49 & 0,66 & 1,55 & $-0,25$ & 3,19 \\
\hline Quirera esbramada & 0,00 & 1,04 & 3,60 & 0,00 & 7,20 \\
\hline Quirera brunida & 1,89 & 3,76 & 5,57 & 4,62 & 6,81 \\
\hline Diferença entre quirera & 1,89 & 2,72 & 1,97 & 4,62 & $-0,39$ \\
\hline Soma das diferenças de quebrados e quirera & 5,38 & 3,38 & 3,52 & 4,37 & 2,80 \\
\hline Farelo (por diferença) & 9,84 & 10,41 & 10,09 & 9,37 & 11,17 \\
\hline
\end{tabular}

Os resultados gerais mostram que usar somente quebrados é mais interessante do que usar só quirera no brunimento de grãos de arroz. Isso pode ser explicado em virtude de o tamanho dos quebrados darem mais suporte físico, por preencherem melhor os espaços intergranulares da massa.

Os resultados estatísticos das relações granulométricas, comparando os cinco tratamentos, em que foram analisados apenas grãos inteiros, estão na Tabela 6.

De acordo com a Tabela 6, nota-se que o tratamento 1 diferiu significativamente dos demais tratamentos, mostrando que houve maior intensidade na quebra de grãos durante o brunimento quando o processo foi realizado usando apenas os grãos inteiros, comparados aos processos em que houve a presença de porções de quebrados e quirera ou um deles. Isso se deve ao fato de as porções menores que o grão preencherem os espaços intergranulares e, com isso, servirem como um suporte físico, proporcionando melhor distribuição das forças de compressão, cisalhamento e torção às quais os grãos ficam sujeitos durante o processo de brunimento. Esses esforços a que os grãos ficam sujeitos durante o brunimento, ocasionam a quebra. Como a massa de grãos possui espaços intergranulares, presume-se que, se esse espaço for preenchido com partículas de grãos, esses servirão de apoio físico aos grãos inteiros, fazendo com que as forças sejam distribuídas em área maior, diminuindo o esforço de um 
grão contra o outro e dos grãos contra o equipamento e, conseqüentemente, diminuindo as quebras resultantes, obtendo-se maior rendimento de engenho.

TABELA 6. Valores médios em gramas da diferença entre grãos de arroz inteiros antes e depois do processo de brunimento ${ }^{1}$.

\begin{tabular}{cc}
\hline Tratamento & Diferença de Inteiros $^{2}$ \\
\hline 1 & $15,22 \mathrm{a}$ \\
2 & $13,79 \mathrm{~b}$ \\
3 & $13,61 \mathrm{~b}$ \\
4 & $13,74 \mathrm{~b}$ \\
5 & $13,97 \mathrm{~b}$ \\
\hline
\end{tabular}

${ }^{1}$ média de dez repetições; ${ }^{2}$ médias seguidas de letras distintas diferem entre si, pelo teste de Duncan $(\mathrm{p}<0,05)$.

Embora não havendo diferença significativa entre os tratamentos $2 ; 3 ; 4$ e 5, observa-se que, numericamente, o tratamento 3 foi o que apresentou o melhor resultado, com maior rendimento de engenho (Tabela 5). Em tese, os espaços vazios entre os grãos inteiros foram preenchidos pelos quebrados, e os espaços vazios entre os quebrados foram preenchidos pela quirera, aumentando, dessa forma, o suporte físico e a resistência à quebra durante o processo de brunimento. Também foi notado que a presença isolada da porção de quebrados foi mais importante para obter maior rendimento de engenho do que a porção de quirera.

Os grupos de tratamentos possuem distribuição normal, uma vez que o teste de KolmogorovSmirnov não foi significativo. O teste de homogeneidade de variâncias (Levene) entre tratamentos apresentou valor $\mathrm{p}=0,046$, o que significa que as variâncias não são homogêneas. Como o valor é próximo a 0,05 , valor para o qual as variâncias entre tratamentos seriam homogêneas e os testes $\mathrm{F}$ são considerados robustos, quando a hipótese de homogeneidade de variância não é atingida, então a análise foi realizada mesmo não havendo homogeneidade de variâncias entre tratamentos. A hipótese de independência também foi alcançada, ou seja, não houve dependência entre o efeito devido ao tratamento e o efeito devido ao erro. O coeficiente de correlação entre as médias e as variâncias foi de 0,0037, que indica uma correlação muito baixa entre os mesmos.

$\mathrm{Na}$ Tabela 7, mostra-se que o tratamento que produziu menor quantidade de grãos quebrados e quirera foi o 5, aquele que possuía o maior conteúdo de quirera do experimento. Observando-se a Tabela 5, nota-se que existiu tendência inversamente proporcional entre a quantidade de quirera esbramada e o somatório das diferenças de grãos quebrados e quirera. Pode-se inferir que parte da quirera adicionada tornou-se farelo durante o processo de brunimento, tendo sido aspirada pelo sistema de ar do brunidor; o mesmo aconteceu com os grãos quebrados que, por sua vez, se tornaram em parte quirera e/ou farelo, pois houve aumento das porções de granulometria mais fina após o processo.

De acordo com a Tabela 7, a soma das diferenças entre quebrados e quirera, antes e após o brunimento, sugere que o tratamento 5 foi o que teve melhor resultado, no qual a média das diferenças entre quebrados e quirera antes e após o brunimento foi de $2,80 \mathrm{~g}$, a menor entre todos os tratamentos. Em análise do resultado da quantidade de farelo [obtido por diferença entre o total de arroz integral (esbramado) e a soma dos inteiros, quebrados e quirera, após o brunimento] produzido devido ao processo de brunimento, o tratamento 5 foi o que produziu maior quantidade média, 11,17 g. Pode-se inferir, então, que parte da quirera, durante o processo de brunimento, se transformou em farelo, somando-se ao farelo produzido pela abrasão das camadas externas dos grãos e outras partes menores de arroz integral. Em função dessa observação, as conclusões foram baseadas na análise das diferenças entre inteiros antes e após o processo de brunimento. 
TABELA 7. Valores médios em gramas da soma das diferenças entre porções de arroz quebrados e quirera antes e depois do processo de brunimento ${ }^{1}$.

\begin{tabular}{cc}
\hline Tratamento & Soma das Diferenças $^{2}$ \\
\hline 1 & $5,38 \mathrm{a}$ \\
2 & $3,38 \mathrm{~b}$ \\
3 & $3,52 \mathrm{~b}$ \\
4 & $4,37 \mathrm{c}$ \\
5 & $2,80 \mathrm{~d}$ \\
\hline${ }^{\prime}{ }^{2}$ média de 10 repetições; ${ }^{2}$ médias seguidas de letras distintas diferem entre si, pelo teste de Duncan $(p<0,05)$.
\end{tabular}

\section{CONCLUSÕES}

Um rendimento de engenho significativamente superior é conseguido, após a operação de brunimento de arroz, quando existe a presença, na massa de grãos a ser brunida, de grãos quebrados e quirera, variando entre $3,6 \%$ e $7,2 \%$ e $1,04 \%$ e $7,2 \%$, respectivamente, o que enfatiza a constatação de que brunir somente grãos inteiros diminui o rendimento de engenho.

O tratamento em que foi feita a adição de quebrados e quirera na massa de grãos a ser brunida, na proporção de $50 \%$ de cada um dos constituintes, apresentou, numericamente, maior rendimento de engenho que os demais tratamentos, embora tenha apresentado diferença significativa apenas do tratamento em que não foi utilizado nenhum fragmento de grão.

A soma de quebrados e quirera, resultante do processo de brunimento, descontadas as quantidades adicionadas, foi significativamente maior para o tratamento em que foram colocados apenas grãos inteiros para brunir e menor para o tratamento em que foi usada apenas quirera junto aos inteiros para brunir, ficando as outras combinações em situação intermediária.

Quanto maior a quantidade de quirera adicionada à massa a ser brunida, maior quantidade de farelo se obtém após o processo, devido a essa granulometria diminuir como decorrência natural do processo.

\section{REFERÊNCIAS}

BRASIL. Ministério da Agricultura. Estatísticas. Disponível em: <http://www.agricultura.gov.br/> Acesso em: 08 jul. 2004.

BRASIL. Ministério da Agricultura. Secretaria Nacional de Abastecimento. Normas de identidade, qualidade, embalagem e apresentação do arroz, Brasília, v.9, n.6/7, jul.1989. 35 p.

BHATTACHARYA, K.R. Breakage of rice during milling, and effect of parboiling. Central Food Technological Research Institute, Mysore, Índia, v.46, n.5, p.478-85, 1969.

CONOVER, W.J. Practical nonparametric statistics. $2^{\text {nd }}$ ed. New York: John Wiley \& Sons, 1980. 493 p.

FOOD AND AGRICULTURE ORGANIZATION OF THE UNITED NATIONS. FAO, FAOSTAT Database. Disponível em: <http://faostat.fao.org> Acesso em: 10 jul. 2004.

HOUSTON, D.F. Rice - Chemistry and technology. St. Paul: American Association of Cereal Chemists, 1972. p.113-15.

INSTITUTO BRASILEIRO DE GEOGRAFIA E ESTATÍSTICA. Levantamento sistemático da produção agrícola. Disponível em: <http://www.ibge.gov.br/>. Acesso em: 26 jun. 2004.

INSTITUTO RIOGRANDENSE DO ARROZ. Produção de arroz: boletim técnico. Lavoura Arrozeira, Porto Alegre, v.46, n.107, p.5-7, 1993. 
INSTITUTO RIOGRANDENSE DO ARROZ. Dados de safra. Disponível em:

<http://www.irga.rs.gov.br/dados.htm>. Acesso em: 07 jul. 2004.

SPADARO, J.J.; MATTHEUS, J.; WADSWORTH, J.I. Milling. In: LUH, B.S. Rice: production and utilization. Connecticut: AVI Publishing, 1980. p.360-402.

VELUPILLAI, L.; PANDEY, J.P. The impact of fissured rice on mill yields. Cereal Chemistry, St. Paul, v.67, n.2, p.118-24, 1990.

VIEIRA, S. Estatística experimental. 2.ed. São Paulo: Atlas, 1999. 185 p.

WADSWORTH, J.I.; MATTHEUS, J. Milling yields and moisture distribution in rough rice.

Transactions of the ASAE, St. Joseph, v.28, n.4, p.1346-52, jul./aug. 1985.

WADSWORTH, J.I.; MATTHEUS, J.; SPADARO, J.J. Milling performance and quality characteristics of Starbonnet variety rice fractionated by rough rice kernel thickness. Cereal Chemistry, St. Paul, v.59, n.1, p.50-4, 1982. 